\title{
Qualitative study of interpretation of reassurance among patients attending rheumatology clinics: "just a touch of arthritis, doctor?"
}

Jenny L Donovan, David R Blake

\begin{abstract}
Objectives To examine commonly used methods of reassurance by clinicians and explore their effect on patients.

Design Qualitative study of tape recordings of in-depth, semistructured interviews with patients before and after consultation and of their consultations with doctors.

Setting NHS specialist rheumatology clinics in two large British cities.

Participants 35 patients selected by consultant rheumatologists from general practitioner referral letters (28 women, 7 men; 24 with inflammatory arthropathies, 11 other rheumatological complaints).

Main outcome measures Patients' perceptions of reassurance.

Results Reassurance was an important part of consultations, whether the diagnosis was clear or uncertain. Clinicians tried to reduce anxiety by emphasising the mildness, early stage, or non-seriousness of the disorder and the likelihood that patients would recover. Patients interpreted reassurance in the context of their own views and perceptions. Doctors' emphasis on the mildness or earliness of the condition raised the spectre of future pain and disability rather than providing reassurance. Patients who felt that their problems were properly acknowledged felt more reassured.

Conclusions Typical patterns of reassurance were not successful because of the differences in perspective of patients and doctors. A key to successful reassurance seemed to be the doctor's ability to acknowledge patients' perspectives of their difficulties.
\end{abstract}

\section{Introduction}

Reassuring patients, both those found not to have serious illness and those requiring further investigation or treatment, is one of the commonest medical tasks. ${ }^{1}$ Yet little research has been conducted into the best methods of imparting reassurance or its effect on patients. Clinicians and textbooks have generally assumed that patients are reassured by clear and confident statements about the diagnosis or the failure to find disease, ${ }^{2}$ with patients who remain anxious after such reassurance at risk of being labelled as neurotic or having abnormal illness behaviour. ${ }^{3}$ Studies have suggested, however, that some patients may be difficult to reassure. Mayou, for example, reported that patients attending a cardiac clinic who were told there was nothing wrong with their hearts expressed fears about heart disease three months later, ${ }^{4}$ and many patients who have been informed of normal results from echocardiography remain anxious about their hearts. ${ }^{2}$ Similarly, $40 \%$ of patients with benign headache who had been reassured by neurologists expressed concern that their symptoms reflected serious disease one month later. $^{5}$

Poor communication is commonly cited as a reason for patients behaving unexpectedly (such as not complying with treatment or expressing unfounded anxieties). ${ }^{67}$ Solutions are then couched in terms of improving the delivery of information from clinician to patient by, for example, providing written information ${ }^{8}$ or more patient-centred consultations. ${ }^{9}$ There have been calls for the provision of patient information to increase reassurance. ${ }^{10}$

Sociological research has shown that patients and doctors can have different perspectives of a clinical encounter, ${ }^{11-13}$ and that patients make sense of their clinical experience in the context of their own views and beliefs. ${ }^{14-16}$ Within a study of information exchange in rheumatology clinics, we explored commonly used methods of reassurance and their interpretation by patients, to investigate why some patients are reassured but others are not in routine consultations.

\section{Participants and methods}

We obtained ethical approval to investigate information exchange between doctors and patients in rheumatology clinics in two large British cities. The patients ranged across the socioeconomic spectrum as one clinic was situated in a deprived inner city area and the other near both affluent and more disadvantaged areas. Consultant rheumatologists selected patients whom they thought had the greatest information needs (new patients with suspected inflammatory arthropathy) from consecutive general practitioner referral letters. Patients were interviewed by JD about a week before their scheduled outpatient appointment. Consultations with the specialist were observed and tape recorded whenever possible. Follow up interviews with patients were undertaken by JD after this and each subsequent consultation. Patients were interviewed until they were discharged or the end of the study (between three months and three years). Further details of the methods have been published. ${ }^{17-19}$

JD conducted semistructured, in-depth interviews with patients in their own homes, following a checklist of topics to ensure that the same issues were covered with each participant..$^{20}$ Topics included the onset or aetiology and experience of joint problems, effects of arthritis on everyday life, experiences of treatments, expectations of the clinic, and views about future health. Interviews after consultations focused on how much patients could recall of what the doctor had told them in the consultation, whether they intended to take the advice and treatments offered, and whether they felt reassured.

Data collection and analysis continued concurrently according to the constant comparison methods of grounded theory and ethnography. ${ }^{20-22}$ Interviews

\section{Department of Social Medicine, University of Bristol, Bristol BS8 2PR \\ Jenny L Donovan reader in social medicine \\ Royal National Hospital for Rheumatic Diseases, Bath BA1 1RL David R Blake professor of bone and joint medicine \\ Correspondence to: J L Donovan jenny.donovan@ bris.ac.uk}

BMJ 2000;320:541-4 
and consultations were tape recorded and fully transcribed. Data relating to the patients of most interest (those with inflammatory arthropathies) were examined first. Data were analysed by detailed scrutiny of the transcripts to identify common themes, which were then coded. Coded segments of text were compared with each other in separate word processing files. ${ }^{23}$ As new transcripts were analysed the themes were refined, focused, or altered. Data were examined for similarities and differences within themes, retaining the context of the interview and the doctor-patient interactions in several ways: cross sectionally, comparing, for example, all baseline interviews; case studies of each individual over time; and focusing on specific themes, such as compliance ${ }^{13}$ or reassurance, including data from linked consultations and interviews. Theoretical sampling was used to allow comparison between, for example, patients with inflammatory conditions and those with other diagnoses such as osteoarthritis. Sampling continued with the aim of achieving data saturation-when new themes no longer emerge from the data. Lengthy descriptive accounts were discussed by the authors to check plausibility and clinical relevance.

This paper focuses on interview and consultation data relating to reassurance. Reassurances provided by clinicians were examined together to determine patterns of presentation. Each clinician's attempt at reassurance was compared with the patient's perception of it in the subsequent interview, with the context of the discussion retained to assist in understanding the patient's view. Negative cases (examples against emerging themes) were investigated closely. The themes that emerged from the data are presented together with illustrative quotations. All names have been changed to preserve anonymity.

\section{Results}

Fifty four patients took part in the main study. ${ }^{17-19}$ This paper focuses on 35 patients (28 women and seven men) who had a baseline interview, at least one consultation, and related follow up interviews tape recorded successfully. The table shows the characteristics of the 35 informants, which were similar to those with incomplete tape recordings. The clinics were conducted by consultants, registrars, senior registrars, and general practitioner clinical assistants. All initial consultations followed the same basic pattern despite their varying lengths (mean 21 minutes, range 12-34 minutes), with doctors taking the history, conducting the examination, and delivering the explanation. Patients were mostly passive. Comparisons between transcripts of consultations and subsequent interviews indicated that most patients were able to recall some or most of the information given to them. ${ }^{24}$

\section{Patterns of reassurance}

As expected, clinicians usually attempted to reassure patients towards the end of the consultation by making statements about treatments, diagnoses, and outcomes. The pattern of reassurance varied depending on the clinical diagnosis. When the diagnosis was of a self limiting or non-inflammatory condition (such as muscle strain or osteoarthritis), the doctor tended to emphasise the non-seriousness of the problem:
Dr C: So I want you to try to think of it as being rather reassured rather than no diagnosis being given and we'll just leave things as they are.

Mary: Well, putting all this aside, the pain in my side is the most worrying of all ... I don't think I imagine it.

Dr C: It's not a question of imagining it. If you can find it, it is there. All I can do is assure you that I can't find anything serious going on ... I'm afraid that with a lot of people like yourself we don't always come to a diagnosis.

(Dr C, registrar; Mary, 49 years, probable osteoarthritis)

When the diagnosis was of an inflammatory disorder such as rheumatoid arthritis or where symptoms were suggestive of this, the reassurance focused on the early or mild nature of the disease:

Dr A (to Maud): The kind of arthritis you have is called rheumatoid arthritis. Now rheumatoid arthritis is a peculiar disease. We do not know what is the cause, but in many people it follows really quite a mild course and it doesn't cause much damage. In others it is a bit more crippling and can cause quite a lot of problems. I think you are going to be quite fortunate in being one of the ones that, although you have got it most of the time, I very much doubt that it will go on and cause you a lot of trouble.

(Dr A, consultant; Maud, 71 years, rheumatoid arthritis)

The explanations given by the doctors were clearly delivered with the intention to reassure, and there was no indication in the consultations themselves that patients were not reassured.

\section{Interpretation of reassurance}

In this study, we were able to explore the patients' interpretations of the reassurance given in the consultations, and these showed that often patients did not interpret the reassurance in the way doctors had intended.

Maud, for example, recalled that Dr A had reassured her that she would not be troubled by her mild rheumatoid arthritis (see above), but this contradicted her experience of her son's progressive disease:

Maud: He said I've got rheumatoid arthritis. I know I'd got arthritis, but I didn't know I had rheumatoid arthritis. But you see it is only in mild form, thank goodness.... I was surprised when he said that because my son has got rheumatoid arthritis, but he has got it really bad.... I don't know, but the doctor said it is only mild, and, of course, my son's was only mild in the beginning, so I hope to God mine doesn't go like that.

The emphasis on the "mildness" of inflammatory disorders led not to reassurance but to fears for the future:

Dr G (to Rita): I have not been able to find any sign of rheumatoid arthritis, which is good .... I think the results of the blood tests will be negative. You have a little mild rheumatoid but so do lots of people, and I think it will not turn out to be anything serious to worry about.

Rita (in interview): The doctor tells me it is mild, not very much, but, you know, from mild it is going to be bad. I know

Characteristics of participants with complete tape recordings

\begin{tabular}{lc} 
Characteristic & $\begin{array}{c}\text { No of } \\
\text { participants } \\
(\mathbf{n = 3 5 )}\end{array}$ \\
\hline Female & 28 \\
\hline$<50$ years old & 21 \\
\hline South Asian or African-Caribbean descent & 2 \\
\hline $\begin{array}{l}\text { Inflammatory diagnosis (rheumatoid arthritis, ankylosing } \\
\text { spondylitis, etc) }\end{array}$ & 24 \\
\hline Other diagnosis (osteoarthritis, trapped nerves, unknown) & 11 \\
\hline
\end{tabular}


that when my sister, when she got this illness, it was [mild], but now it is very bad.

(Dr G, senior registrar; Rita, 49 years, rheumatoid arthritis)

A similar emphasis on the "early stage" of the disease caused concern to patients who felt that they were already suffering enough:

Dr D (to Margaret): I don't think there is any question that you've got an arthritis, and according to the GP's tests it is rheumatoid, but it is in the very early stages and we would certainly do all we possibly can to stop it from damaging your joints.

Margaret (in interview): The doctor said that it was almost definite that it was rheumatoid arthritis, but he thought it was in the early stages. And to me, if that is it in the first stages-I can stand pain, I can grit my teeth and put pain at the back of my mind-but if that is the first stages, then I can see why it gets really bad, that it does cripple.... If that is the pain on the first stages, then what [pause] er, will it be like? (Dr D, GP clinical assistant; Margaret, 50 years, rheumatoid arthritis)

Patients were also not reassured when doctors contradicted their own views about their problems or seemed not to take their difficulties seriously enough, whether the diagnosis was uncertain (Richard) or clear (Cynthia):

Dr B (to Richard): Certainly examining you today, the trigger finger in your thumb is irrelevant. We can treat that if it is a problem, but I don't think it's anything to worry about. The slight concern is whether the what we call "polyarthralgia"-aches and stiffness in the joints-signifies any underlying disease going on. It's difficult to tell. It's quite likely that there won't be, or that all the tests will be normal .... Most of the time we get a lot of people who present with aches and pains and we never find anything. Very occasionally, it can be the prodrome-the beginning of a more definite form of joint trouble, but there is very little that at the moment would make me say that's what is going on here.

Richard (in interview): He said the trigger finger is not related to the problem I've got, which sounds really peculiar to me because ... it seems a bit of a coincidence that I have got something totally unrelated which to me is totally related. He doesn't see me in the mornings, hobbling around. Quite honestly, he treats it very differently, which is a shame. I'm not looking for sympathy .... I think I want him to be aware, really, and a bit more concerned over my health and welfare.

(Dr B, consultant; Richard, 39 years, problems never diagnosed)

Dr E (to Cynthia): I think what we are going to find out is that you've got some wear and tear arthritis, OK? Certainly in your knees and I suspect that's the reason your right hindquarter hurts, because of your back rather than hip .... On examining you, the only real thing I could find was that your knees have got quite a lot of creaking in them and your hands have the early stages of osteoarthritis that tends to run in families.

Cynthia (in interview): He said he didn't think it was in me hip, he said it was in me back, but I'd swear one hip is bigger than the other. They say doctors differ and patients die, and I think that's true .... I think [the doctor] understands my problems, but they're not that dramatic to him. They are to me because I'm the one who is suffering. He doesn't think it's as desperate as I think it is. He thinks, "you've got arthritis like millions of others." But I've got to live with it.

(Dr E, registrar; Cynthia, 43 years, osteoarthritis)

\section{Key to successful reassurance}

Overwhelmingly, one theme emerged consistently in relation to reassurance: whether patients perceived that the doctor had acknowledged their difficulties. In the quotations above, patients' concerns about doctors not understanding their problems are evident. In contrast, if patients felt their difficulties had been heard by the doctor and acknowledged appropriately, reassurance could be achieved:

Dora: He said, "You are not too bad really, it is only wear and tear of your bones during the years." He said, "That's because of your five children, that is." I went in heavy laden, but I came out feeling very light.

(Dora, 76 years, osteoarthritis and rheumatoid arthritis)

\section{Discussion}

Reassuring patients is a critical medical task. The belief that patients will be reassured simply by clear and confident statements by clinicians has recently come under scrutiny, with the consistent finding that many patients remain concerned after such reassurance. ${ }^{25}$

Patients attending the clinics in this study ranged from those with minor complaints to those with severe disabling arthritis. In this context, doctors attempted to reassure new patients by emphasising the nonseriousness of their disorder, its early stage, and its likely mild prognosis. Interviews with patients, however, showed that they did not interpret such statements as reassuring because of their perception that symptoms already affected everyday life and because of the implications of future pain and disability that such statements engendered. This study thus reflects sociological research that has shown that differences in perspective can occur between clinicians and patients, even though each may be rational and reasonable in its own terms, ${ }^{11-13}$ and also that lay beliefs about illness and health care are sensitive, sophisticated, and rational. ${ }^{14-16}$

This study was limited to patients attending rheumatology clinics. Although not the initial focus of the study, the findings about reassurance were remarkably consistent across the range of disorders and the seniority and clinical experience of the doctors. The plausibility of the findings suggests that these issues may apply more widely, although this remains to be tested.

Clinicians face many difficult tasks in the short consultation with patients. In this study, they struggled particularly with how to inform patients about conditions with an unpredictable but potentially disabling course

\section{What is already known on this topic}

Reassurance is a crucial clinical task

Methods of imparting reassurance successfully are poorly understood

\section{What this study adds}

Typical methods of imparting reassurance, including allaying fears and anxieties by emphasising the minor or early nature of a disease, are not necessarily interpreted as reassuring by patients

Patients make sense of the doctor's words within the context of their own views and experiences

Acknowledgment of patients' views of their condition is important for reassurance 
and with how to express uncertainty. Although patients were mostly able to recall what the doctor had said, they often interpreted particular terms (such as mild) differently from what was intended by the clinician. Successful and unsuccessful reassurance seemed to hinge on the patient's perception that the doctor had understood and acknowledged his or her current difficulties and indicated this using appropriate and acceptable terminology.

In conclusion, this study suggests that patients may be successfully reassured if clinicians avoid loaded terms such as "mild" and "early stages" and try to acknowledge patients' perspectives that their difficulties are serious. Attempting to reassure patients in this way might seem to require more time, but we found that it was the perception of having symptoms and problems acknowledged that seemed to matter, not more time itself.

We thank Bill Fleming for support, the clinicians who participated in this study, and the patients who contributed so much information. The Department of Social Medicine at the University of Bristol is the main centre for the MRC Health Services Research Collaboration.

Contributors: DB initiated the study, and JD developed the design of the study. JD carried out the interviews, observations, and data analysis and acts as guarantor. JD and DB wrote the paper.

Funding: Arthritis and Rheumatism Council.

Competing interests: None declared.

1 Fitzpatrick R. Telling patients there is nothing wrong. BMJ 1996;313: $311-12$.
2 McDonald IG, Daly J, Jelinek VM, Panetta F, Gutman JM. Opening Pandora's box: the unpredictability of reassurance by a normal test result. BMJ 1996;313:329-32.

3 Pilowsky I. Abnormal illness behaviour. Br J Med Psychol 1969;42:347-51. 4 Mayou R. The nature of bodily symptoms. Br J Psychiatry 1976;129:55-60.

5 Fitzpatrick R, Hopkins A. Referrals to neurologists for headaches not due to structural disease. J Neurol Neurosurg Psychiatry 1981:44:1061-7.

6 Bartlett EE, Grayson M, Barker R, Levine DM, Golden A, Libber S. The effects of physician communication skills on patient satisfaction, recall and adherence. J Chron Dis. 1984;37:755-64.

7 Francis V, Korsch B, Morris M. Gaps in doctor-patient communication N Engl J Med 1969;280:535-8.

8 Patient compliance. Ann Pharmacotherapy 1993;27:S5-24.

9 Henbest RJ, Stewart M. Patient-centredness in the consultation: does it really make a difference? Fam Pract 1990;7:28-33.

10 Kessel N. Reassurance. Lancet 1979;i:1128-33.

11 Freidson E. Profession of medicine. New York: Dodd Mead and Co, 1970.

12 Mishler E. The discourse of medicine. Norwood, New Jersey: Abler, 1984

13 Silverman D. Communication and medical practice. London: Sage, 1987.

4 Blaxter M. The causes of disease: women talking. Soc Sci Med, 1983;17: $59-69$

15 Williams SJ, Calnan M. Modern medicine: lay perspectives and experiences. London: UCL Press, 1996.

16 Eyles JD, Donovan JL. The social effects of health policy: experiences of health and health care in contemporary Britain. Aldershot: Avebury, 1990.

17 Donovan JL, Blake DR, Fleming WG. The patient is not a blank sheet: lay beliefs and their relevance to patient education. $\mathrm{Br} J$ Rheumatol 1989;28:58-61.

18 Donovan JL. Patient education and the consultation-the importance of lay beliefs. Ann Rheum Dis 1991;50:418-21.

19 Donovan JL, Blake DR. Patient non-compliance: deviance or reasoned decision-making? Soc Sci Med 1992;34:507-13.

20 Hammersley M, Atkinson P. Ethnography. London: Tavistock, 1983.

21 Glaser BG, Strauss AL. The discovery of grounded theory. Chicago: Aldine, 1967.

22 Mays N, Pope C. Qualitative research in health care. London: BMJ Publishing, 1996.

23 Miles MB, Huberman EM. Qualitative data analysis. 2nd ed. London: Sage, 1994.

24 Donovan JL. Patient decision making: the missing ingredient in compliance research. Int J Technol Assess Health Care 1995;11:443-55.

(Accepted 13 December 1999)

\title{
Open access follow up for inflammatory bowel disease: pragmatic randomised trial and cost effectiveness study
}

\author{
J G Williams, W Y Cheung, I T Russell, D R Cohen, M Longo, B Lervy
}

\section{School of \\ Postgraduate \\ Studies in Medical \\ and Health Care, \\ Morriston Hospital, \\ Swansea SA6 6NL \\ J G Williams \\ director \\ W Y Cheung \\ lecturer \\ B Lervy \\ senior lecturer in \\ general practice \\ Department of \\ Health Sciences \\ and Clinical \\ Evaluation, \\ University of York, \\ Heslington, York \\ YO10 5DD \\ I T Russell \\ professor of health \\ sciences \\ continued over}

BMJ 2000;320:544-8

\begin{abstract}
Objective To evaluate whether follow up of patients with inflammatory bowel disease is better through open access than by routine booked appointments. Design Pragmatic randomised controlled trial. Setting Two district general hospitals in Swansea and Neath, Wales.

Participants 180 adults (78 with Crohn's disease, 77 ulcerative or indeterminate colitis, 25 ulcerative or idiopathic proctitis) recruited from outpatient clinics during October 1995 to November 1996.

Intervention Open access follow up according to patient need.

Main outcome measures Generic (SF-36) and disease specific (UK inflammatory bowel disease questionnaire UKIBDQ) quality of life, number of primary and secondary care contacts, total resource use, and views of patients and general practitioners. Results There were no differences in generic or disease specific quality of life. Open access patients had fewer day visits $(0.21 v 0.42, \mathrm{P}<0.05)$ and fewer outpatient visits ( $4.12 v 4.64, \mathrm{P}<0.01$ ), but some patients had difficulty obtaining an urgent appointment. There were no significant differences in
\end{abstract}

specific investigations undertaken, inpatient days, general practitioner surgery or home visits, drugs prescribed, or total patient borne costs. Mean total cost in secondary care was lower for open access patients $(\mathrm{P}<0.05)$, but when primary care and patient borne costs were added there were no significant differences in total costs to the NHS or to society. General practitioners and patients preferred open access.

Conclusions Open access follow up delivers the same quality of care as routine outpatient care and is preferred by patients and general practitioners. It uses fewer resources in secondary care but total resource use is similar. Better methods of ensuring urgent access to outpatient clinics are needed.

\section{Introduction}

Gastroenterology is a busy medical specialty with a large and expanding outpatient workload. ${ }^{1}$ Many patients with gastrointestinal disorders have chronic relapsing disease and some, particularly those with inflammatory bowel disease, are traditionally kept under continuing follow up. This reflects the wishes of general practitioners ${ }^{2}$ as well as specialists, who feel 